Arq. Bras. Med. Vet. Zootec., v.69, n.3, p.593-596, 2017

\title{
Dispneia expiratória restritiva em um gato com fibrose pulmonar idiopática: relato de caso
}

\author{
[Restrictive expiratory dyspnea in a cat with idiopathic pulmonary fibrosis: case report] \\ C.O. Pereira ${ }^{1}$, F.V.A. Costa ${ }^{2}$, D.C. Gomes ${ }^{3}$, P.N. Kasper $^{4}$, A.B. Vieira ${ }^{5}$, D. Driemeier ${ }^{2}$ \\ ${ }^{1}$ Médica veterinária autônoma \\ ${ }^{2}$ Universidade Federal do Rio Grande do Sul - Porto Alegre, RS \\ ${ }^{3}$ Aluno de pós-graduação - Universidade Federal do Rio Grande do Sul - Porto Alegre, RS \\ ${ }^{4}$ Aluna de pós-graduação - Universidade Federal de Santa Maria - Porto Alegre, RS \\ ${ }^{5}$ Instituto Qualittas - Rio de Janeiro, RJ
}

\begin{abstract}
RESUMO
As doenças pulmonares intersticiais constituem um grupo de doenças difusas do parênquima pulmonar, no qual a fibrose pulmonar intersticial está incluída. Histologicamente, esta se caracteriza por hiperplasia de pneumócitos tipo II, hiperplasia ou hipertrofia de músculo liso e fibrose. Embora a patogenia da fibrose pulmonar intersticial não esteja bem elucidada, devido às semelhanças microscópicas encontradas nos pneumócitos tipo II em felinos e na forma familiar da doença em humanos, acredita-se que haja caráter genético para o seu desenvolvimento. Os sinais clínicos frequentemente relatados incluem desconforto respiratório, cianose, letargia e perda de peso. Devido ao caráter progressivo e à ausência de tratamento específico, a doença apresenta prognóstico desfavorável. Foi atendida uma gata de 12 anos de idade, com histórico de dispneia há 20 dias. Ao exame clínico, o animal apresentou dispneia expiratória restritiva, crepitação à ausculta torácica e foi visualizado padrão intersticial ao exame radiográfico do tórax. A paciente foi submetida à punção com agulha fina de tecido pulmonar e veio a óbito algumas horas após o procedimento, apresentando insuficiência respiratória aguda. No exame histológico do tecido pulmonar, foi verificada a ocorrência de fibrose pulmonar idiopática. $\mathrm{O}$ objetivo do presente trabalho é relatar um caso de dispneia expiratória restritiva em um felino doméstico devido à fibrose pulmonar idiopática, já que, segundo o conhecimento dos autores, não há nenhum relato da ocorrência da doença no país.
\end{abstract}

Palavras-chave: crepitação, doenças pulmonares intersticiais, pneumócitos tipo II

\begin{abstract}
Interstitial lung diseases are a group of diffuse parenchymal lung diseases in which interstitial lung fibrosis is included. Histologically, it is characterized by type II pneumocyte hyperplasia, hypertrophy or hyperplasia of smooth tissue and fibrosis. Although the pathogenesis of interstitial lung fibrosis has not been elucidated, due to the microscopic similarities found in type II pneumocytes in cats and familial form of the disease in humans, it is believed that there is a genetic trait for development. The frequently reported clinical signs include respiratory distress, cyanosis, lethargy, and weight loss. Due to the progressive nature and the absence of specific treatment, the disease has a poor prognosis. A 12-year-old cat with dyspnea for 20 days was assisted. The animal underwent fine needle aspiration of lung tissue and died few hours after the procedure, with acute respiratory failure. Upon histological examination of lung tissue, the occurrence of idiopathic pulmonary fibrosis was found. The aim of this study is to report a case of restrictive expiratory dyspnea in a domestic feline due to idiopathic pulmonary fibrosis, because, according to our knowledge, there is no report on the occurrence of the disease in our country.
\end{abstract}

Keywords: crackle, interstitial lung diseases, type II pneumocytes

Recebido em 29 de abril de 2015

Aceito em 7 de julho de 2016

E-mail: pereiracamilavet@gmail.com 


\section{Pereira et al.}

\section{INTRODUÇÃO}

As doenças pulmonares intersticiais (DPI) constituem um grupo de doenças difusas do parênquima pulmonar, caracterizadas por lesões localizadas particularmente no parênquima alveolar, no qual a fibrose pulmonar idiopática (FPI) está incluída (Cushley et al., 1999). Histologicamente, gatos com FPI apresentam proliferação de pneumócitos tipo II, hiperplasia ou hipertrofia de músculo liso, e a fibrose é encontrada, pelo menos, em moderada magnitude (Evola et al., 2014). A patogenia da doença não está bem elucidada. No entanto, as características microscópicas dos pneumócitos tipo II observadas em gatos com FPI são semelhantes à forma familiar dessa doença em humanos, sugerindo, portanto, caráter genético para o seu desenvolvimento (Thomas et al., 2002). Em razão dessa essa similaridade, os gatos são utilizados como modelo para o estudo da doença em humanos (Williams et al., 2004). Os sinais clínicos frequentemente relatados incluem desconforto respiratório, cianose, letargia e perda de peso (Evola et al., 2014). Devido ao caráter progressivo e à ausência de tratamento específico, a doença apresenta prognóstico desfavorável (Cohn et al., 2004). O presente trabalho visa relatar um caso de dispneia expiratória restritiva em um felino doméstico devido à FPI, já que, segundo o conhecimento dos autores, não há nenhum relato da ocorrência da doença nessa espécie no Brasil.

\section{CASUÍ́STICA}

Uma gata, sem raça definida, de 12 anos de idade, foi atendida no Hospital de Clínicas
Veterinárias da Universidade Federal do Rio Grande do Sul com histórico de dispneia havia 20 dias. Durante o exame físico, foi verificada crepitação à ausculta torácica e foi observado esforço respiratório superficial de ocorrência rápida durante a expiração, caracterizando dispneia expiratória restritiva. Ao exame radiográfico de tórax, foi observada a presença de infiltrado pulmonar grave, indicando padrão intersticial (Fig. 1). Não foram verificadas alterações hematológicas e bioquímicas nos exames realizados. A terapêutica instituída incluiu prednisolona na dose de $2 \mathrm{mg} / \mathrm{kg}$, por via oral, a cada 12 horas, por sete dias, amoxicilina com clavulanto de potássio na dose de $10 \mathrm{mg} / \mathrm{kg}$, por via oral, a cada 12 horas, por sete dias, e fenbendazol na dose de $50 \mathrm{mg} / \mathrm{kg}$, por via oral, a cada 24 horas, por 15 dias. Não foi verificada melhora com o tratamento e, após 10 dias, o animal foi reavaliado. Ao exame clínico, a dispneia estava mais acentuada. Além disso, a paciente permaneceu em posição ortopneica e apresentou cianose à manipulação. Foi prescrita inalação, por via oral, com sulfato de salbutamol, na dose de $100 \mathrm{mcg}$, a cada 12 horas, e solicitada a realização de punção com agulha fina (PAF) de tecido pulmonar com o animal sedado. Algumas horas após a realização do procedimento, o animal veio a óbito, apresentando insuficiência respiratória aguda. O corpo foi encaminhado para necropsia. No exame microscópico, foi verificada acentuada fibrose intersticial difusa com hiperplasia de músculo liso (Fig. 2) e proliferação de pneumócitos tipo II. Adicionalmente, foi verificado infiltrado inflamatório mononuclear leve nas células do epitélio alveolar.

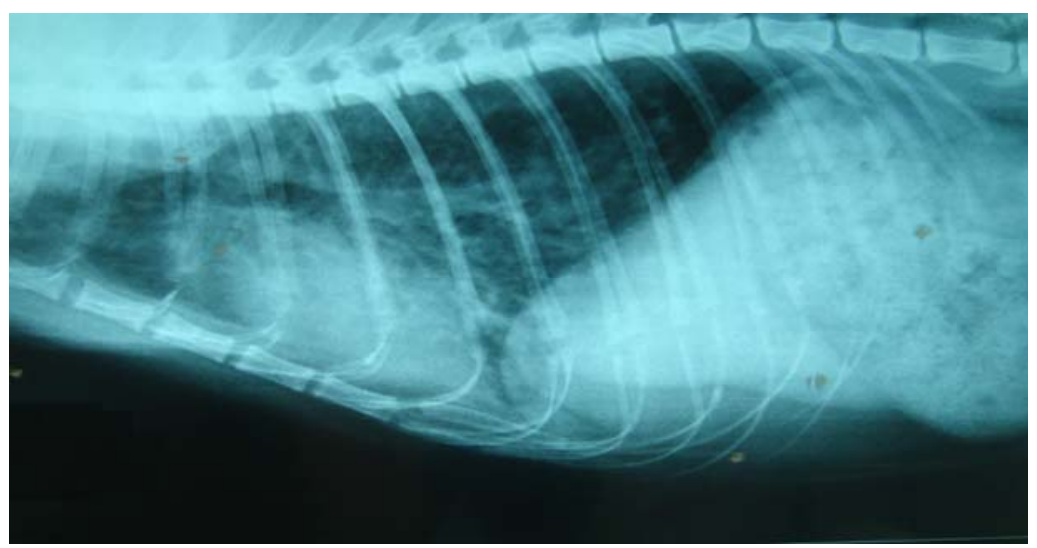

Figura 1. Radiografia de tórax na posição laterolateral de um felino doméstico com infiltrado pulmonar grave, caracterizando padrão intersticial devido à fibrose pulmonar idiopática. 


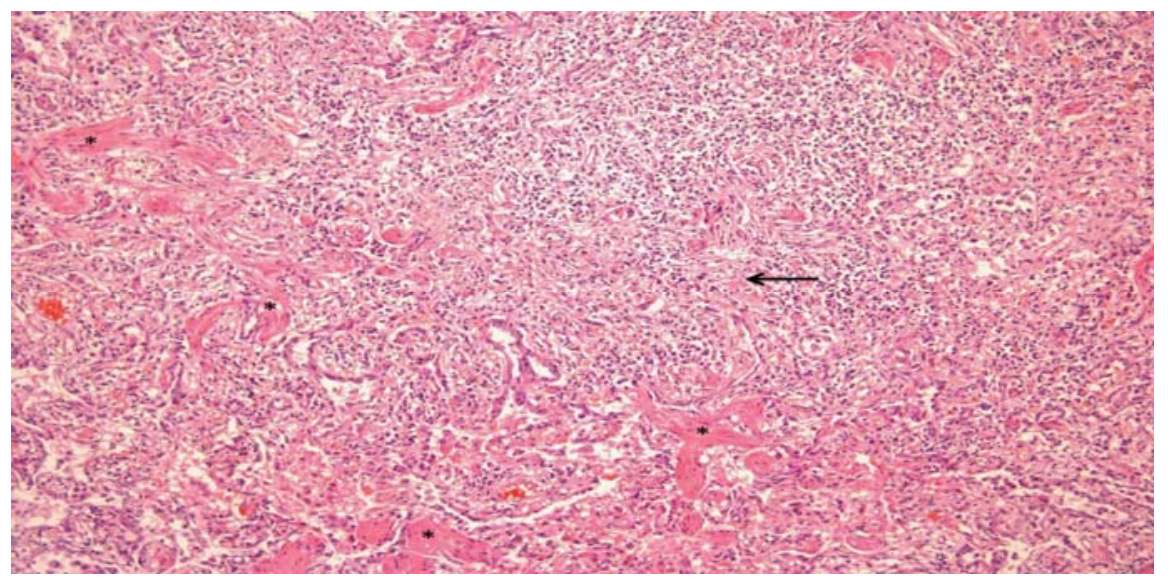

Figura 2. Exame histológico de um felino doméstico com fibrose pulmonar idiopática, pulmão com proliferação de músculo liso (*) e de tecido conjuntivo fibroso (seta). Coloração de hematoxilina e eosina, aumento de 10x.

\section{DISCUSSÃO}

O momento em que a dificuldade respiratória ocorre e o padrão da sua ocorrência contribuem para o direcionamento da estrutura responsável pelo seu acontecimento. Quando a dificuldade respiratória ocorre durante a expiração, geralmente está relacionada à doença do trato respiratório inferior (Morais, 2010), conforme foi observado na paciente. Animais com padrão respiratório restritivo apresentam respiração rápida e superficial (Lee e Dobratz, 2004) que pode ser silenciosa ou sonora à auscultação torácica. O som adventício durante a auscultação do tórax é classificado como crepitação quando ocorre de forma descontínua e caracteriza-se por ser curto e semelhante a uma explosão. Doenças que acometem o parênquima pulmonar, como a FPI, cursam com dispneia restritiva sonora (Morais, 2010), como foi observado no presente caso. A PAF possui algumas limitações para o diagnóstico de FPI. As mais importantes incluem a inabilidade de avaliação das alterações da arquitetura pulmonar e dos níveis de fibrose presentes no pulmão (Deberry et al., 2002). Por essas razões, a PAF não pode ser considerada um meio diagnóstico para FPI em gatos, embora seja útil para descartar outras causas mais comuns de dispneia, como neoplasias e desordens infecciosas do tecido pulmonar (Cohn et al., 2004), tendo sido realizada por esta razão no presente caso relatado. Em humanos, o diagnóstico de FPI é realizado por meio do exame histológico do tecido pulmonar (Fujita et al., 2001). Histologicamente, gatos com FPI possuem tecido pulmonar com padrão multifocal que se caracteriza por apresentar parênquima relativamente normal entremeado por tecido afetado. As alterações histológicas mais frequentemente observadas em felinos domésticos com FPI incluem metaplasia de tecido liso, fibrose intersticial, metaplasia de epitélio alveolar e inflamação de parênquima (Williams et al., 2004). A paciente do caso relatado apresentava as principais alterações verificadas na FPI em sua espécie. Os pneumócitos tipo II em gatos hígidos possuem corpos lamelares com membranas fosfolipídicas e microvilosidades em sua superfície. Quando os pneumócitos tipo II dessa espécie estão alterados devido à FPI, eles se apresentam aumentados e com múltiplas estruturas lamelares condensadas e aumentadas (Williams et al., 2004), como foi verificado ao exame histológico da paciente.

\section{CONCLUSÃO}

Embora o atendimento a gatos dispneicos seja uma rotina na clínca de felinos, inúmeras vezes os animais vêm a óbito de forma aguda e sem diagnóstico definitivo. Possivelmente, esta seja uma das razões pelas quais há apenas seis trabalhos em todo o mundo de FPI em gatos. Portanto, a FPI deve constar como possibilidade diagnóstica em gatos com dificuldade respiratória para que haja maior possibilidade de entendimento da patogenia da doença $\mathrm{e}$ consequente desenvolvimento de terapêutica direcionada, o que poderia promover avanços na medicina veterinária e na humana, já que os gatos são usados como modelo para estudo da doença em outras espécies. 


\section{REFERÊNCIAS}

COHN, L.A.; NORRIS, C.R.; HAWKINS, E.S. et al. Identification and characterization of idiopathic pulmonary fibrosis-like conditions in cats. J. Vet. Int. Med., v.18, p.632-641, 2004.

CUSHLEY, M.J.; DAVISON, A.G.; DUBOIS, R.M. et al. The diagnosis, assessment and treatment of diffuse parenchymal lung disease in adults. Thorax, v.54, Suppl.1, p.s1-s28, 1999.

DEBERRY, J.D.; NORRIS, C.R.; SAMIL, V.F. et al. Correlation between fine-needle aspiration cytopathology and histopathology of the lung in dogs and cats. J. Am. Anim. Hosp. Assoc., v.38, p.327-336, 2002.

EVOLA, M.G.; EDMONDSON, E.F.; REICHLE, J.K. et al. Radiographic and histopathologic characteristics of pulmonary fibrosis in nine cats. Vet. Radiol. Ultrasound, v.55, p.133-140, 2014.

FUJITA, J.; YOSHINOUCHI, T.; OHTSUKI, Y. et al. Non-specific interstitial pneumonia as pulmonary involvement of systemic sclerosis. Ann. Rheumatol. Dis., v.60, p.281-283, 2001.
LEE, J.A.; DROBATZ, K.J. Respiratory distress and cyanosis in dogs, In: KING, L.G. (Ed.). Textbook of respiratory disease in dogs and cats. Philadelphia: WB Saunders, 2004. p.1-11.

MORAIS, H.A. Why is this patient dyspneic? In: SOCIEDAD LATINOAMERICANA DE MEDICINA VETERINARIA DE EMERGENCIA Y CUIDADOS INTENSIVOS, 2010, Buenos Aires. Proceedings... Buenos Aires: SLAMVECI, 2010. Available in: $<$ http://www.laveccs.org/biblioteca/file/dyspnea $\% 20$ in $\% 20$ dogs $\% 20$ and $\% 20$ cats.pdf.pdf $>$.

Accessed in: 08 Mar. 2015.

THOMAS, A.Q.; LANE, K.; PHILLIPS, J. et al. Heterozygosity for a surfactant protein $\mathrm{c}$ gene mutation associated with usual interstitial pneumonitis and cellular nonspecific interstitial pneumonitis in one kindred. Am. J. Respir. Crit. Care Med., v.165, p.1322-1328, 2002.

WILLIAMS, K.; MALARKEY, D.; COHN, L. et al. Identification of spontaneous feline idiopathic pulmonary fibrosis. Chest J., v.125, p.22782288, 2004. 